\title{
Kinases of two strains of Mycoplasma hyopneumoniae and a strain of Mycoplasma synoviae: An overview
}

\author{
Alexandre Melo Bailão, Juliana Alves Parente, Maristela Pereira and Célia Maria de Almeida Soares \\ Laboratório de Biologia Molecular, Instituto de Ciências Biológicas, Universidade Federal de Goiás, \\ Goiânia, Goiás, Brazil.
}

\begin{abstract}
Mycoplasma synoviae and Mycoplasma hyopneumoniae are wall-less eubacteria belonging to the class of Mollicutes. These prokaryotes have a reduced genome size and reduced biosynthetic machinery. They cause great losses in animal production. M. synoviae is responsible for an upper respiratory tract disease of chickens and turkeys. M. hyopneumoniae is the causative agent of enzootic pneumonia in pigs. The complete genomes of these organisms showed 17 ORFs encoding kinases in M. synoviae and 15 in each of the M. hyopneumoniae strain. Four kinase genes were restricted to the avian pathogen while three were specific to the pig pathogen when compared to each other. All deduced kinases found in the non pathogenic strain (J[ATCC25934]) were also found in the pathogenic $M$. hyopneumoniae strain. The enzymes were classified in nine families composing five fold groups.
\end{abstract}

Key words: Mycoplasma, kinases, genomes.

Received: April 12, 2006; Accepted: October 5, 2006.

\section{Introduction}

Edmond Nocard and Emile Roux successfully cultivated the agent of the contagious bovine pleuropneumonia, Mycoplasma mycoides, over a century ago (Nocard and Roux, 1898). Since that time, approximately 111 species of the genus Mycoplasma have been identified in animals. These and other 102 species comprise the class of Mollicutes (Minion et al., 2004). These prokaryotes are known as the smallest self replicating organisms (Glass et al., 2000; Westberg et al., 2004). Most members of this class are pathogenic and colonize a wide variety of hosts, such as animals, plants and insects. Mollicutes represent a group of Low-G+C-content eubacteria that are phylogenetically related to the Clostridium-StreptococcusLactobacillus branch of the phylum (Woese et al., 1980; Rogers et al., 1985; Maniloff, 1992). As a consequence of the reduced biosynthetic machinery, Mollicutes live in nature as obligate parasites and depend on the uptake of many essential molecules from their hosts (Papazisi et al., 2003). Thus, they have been considered model systems for defining the minimal set of genes required for a living cell (Morowitz, 1984).

Although, Mollicutes have a simple genome, mycoplasma diseases are complex and relatively unknown

Send correspondence to Célia Maria de Almeida Soares. Laboratório de Biologia Molecular, Sala 206, Instituto de Ciências Biológicas II, Universidade Federal de Goiás, Campus Samambaia, 74001-970 Goiânia, Goiás, Brazil. E-mail: celia@ icb.ufg.br.
(Minion et al., 2004). One hallmark of these diseases is the chronicity (Ross, 1992), but equally important is the ability to alter or circumvent the immune response and to potentiate diseases caused by other pathogens (Ciprian et al., 1988; Thacker et al,. 1999; Muhlradt, 2002). A key factor in the ability of mycoplasmas to establish a chronic infection is their genome flexibility, which allows them to produce a highly variable mosaic of surface antigens (Citti and Rosengarten, 1997; Chambaud, et al., 1999; Shen et al., 2000 Assunção et al., 2005).

In the last years, the genomes of ten mycoplasma species have been completely sequenced (Himmelreich et al., 1996; Glass et al., 2000; Chamabaud et al., 2001; Sasaki et al., 2002; Berent and Messik, 2003; Papazisi et al., 2003; Westberg et al., 2004; Jaffe et al., 2004; Minion et al., 2004). Recently, the complete genomes of a pathogenic (7448) and nonpathogenic (J [ATCC 25934]) strains of Mycoplasma hyopneumoniae, as well as the complete genome of a strain (53) of Mycoplasma synoviae (Vasconcelos et al., 2005) were obtained. Both species cause great adverse impact on animal production. M. hyopneumoniae is the causative agent of porcine enzootic pneumonia, a mild, chronic pneumonia of swine, commonly complicated by opportunistic infections with other bacteria (Ross, 1992). Like most other members of the order Mycoplasmatales, M. hyopneumoniae is infective for a single species, but the mechanisms of host specificity are unknown. M. synoviae is the major poultry pathogen 
throughout the world, causing chronic respiratory disease and arthritis in infected chickens and turkeys (Allen et al., 2005).

Kinases play indispensable roles in numerous cellular metabolic and signaling pathways, and they are among the best-studied enzymes at the structural, biochemical, and cellular levels. Despite the fact that all kinases use the same phosphate donor (in most cases, ATP) and catalyze apparently the same phosphoryl transfer reaction, they display remarkable diversity in their structural folds and substrate recognition mechanisms, probably due largely to the extraordinarily diverse nature of the structures and properties of their substrates (Cheek et al., 2005).

Complete genome sequencing identified 679, 681 and 694 Open Reading Frames (ORF) of $M$. hyopneumoniae strains J (Mhy-J), 7448 (Mhy-P) and $M$. synoviae strain 53 (Msy), respectively. Analysis of these mycoplasma genomes by bioinformatics tools identified 15 Mhy-J ORFs, 15 Mhy-P ORFs and 17 Msy ORFs, all of which encode kinases. Due to the biological importance of these enzymes we expect that their study will improve the comprehension of the reduced biosynthetic pathways in mollicutes.

\section{Methods}

By using previous results from the complete genomes of M. synoviae and M. hyopneumoniae, J and 7448 strains as input to BLAST search tools we obtained 17 ORFs encoding kinase homologues in M. synoviae and 15 in both strains of M. hyopneumoniae. Putative biological functions of the kinases were deduced by using Pfam interface and InterPro information. The classification of enzymes into fold groups and families was performed by following the scheme described by Cheek et al. (2005). In brief, all kinase sequences from the NCBI non-redundant database were assigned to a set of 57 profiles describing catalytic kinase domains by using the hmmsearch program of the HMMR2 package (Eddy, 1998). Sequences from each Pfam/COG profile presenting significant PSI-BLAST (Altschul et al., 1997) hits to each other were clustered into the same family. Families in the same fold group share structurally similar nucleotide-binding domains that have the same architecture and topology (or are related by circular permutation) for at least the core of the domain. Multiple sequence alignments were generated using the ClustalX 1.81 software (Thompson et al., 1997). The amino acid sequence relationships were generated with the predicted protein sequences obtained from 47 kinase-encoding ORFs identified in the complete genome sequences of $M$. synoviae and $M$. hyopneumoniae. A phylogenetic tree was constructed by multiple sequence alignments (pairwise alignments) using the Clustal X 1.81 program (Thompson et al., 1997) and visualized by using the TreeView software. The tree was constructed by using the minimum evolution (neighbor-joining) method (Saitou and Nei, 1987).
Robustness of branches was estimated using 100 bootstrap replicates.

\section{Results and Discussion}

\section{Mycoplasma kinases}

In this study we briefly review the kinase genes of $M$. hyopneumoniae and M. synoviae, and we describe a classification and metabolic comparative analysis of kinases of these organisms. In the genome sequences we identified a total of 47 kinase-encoding ORFs which are related to several different biosynthetic pathways, such as purine and pyrimidine metabolism, glycolysis, pyruvate metabolism, as well as cofactor metabolism and others (Table 1). The two $M$. hyopneumoniae strains have equal numbers of the same kinases-encoding ORFs. Three of these are absent in $M$. synoviae (glycerol kinase, glucokinase and 5-dehydro-2deoxygluconokinase) which has an additional 17 ORFs that encode kinases. Four of them (three ORFs encoding deoxyguanosine kinase and one ORF encoding N-acetylmannosamine kinase) are exclusive to this species when compared to M. hyopneumoniae strains J and 7448 (Table 1). These differences between the two species could be related to specific nutritional requirements found by each pathogen in its respective host. All kinases found in the pathogenic strain

Table 1 - Kinases identified in the M. synoviae and M. hyopneumoniae genomes.

\begin{tabular}{|c|c|c|c|}
\hline \multirow[t]{2}{*}{ Gene product } & \multicolumn{3}{|c|}{$\begin{array}{l}\text { Presence of ORFs encoding kinase } \\
\text { in mycoplasmas }\end{array}$} \\
\hline & Msy ORF & Mhy-J ORF & Mhy-P ORF \\
\hline Deoxyguanosine kinase & $\begin{array}{l}\text { MS0380 } \\
\text { MS0140 } \\
\text { MS0141 }\end{array}$ & - & - \\
\hline $\begin{array}{l}\mathrm{N} \text {-acetylmannosamine } \\
\text { kinase }\end{array}$ & MS0195 & - & - \\
\hline $\begin{array}{l}\text { Serine/threonine-protein } \\
\text { kinase }\end{array}$ & MS0121 & - & - \\
\hline Pyruvate kinase & MS0648 & МHJ0122 & МHР0126 \\
\hline Adenylate kinase & MS0580 & МНJ0170 & МHР0174 \\
\hline Thymidine kinase & MS0521 & МНJ0610 & МНР0608 \\
\hline Cytidylate kinase & MS0143 & МHJ0065 & MHP0069 \\
\hline Guanylate kinase & MS0123 & МНJ0149 & MHP0153 \\
\hline Phosphoglycerate kinase & MS0114 & МHJ0487 & MHP0490 \\
\hline Uridylate kinase smbA & MS0677 & MHJ0536 & MHP0535 \\
\hline 6-phosphofructokinase & MS0296 & MHJ0107 & MHP0111 \\
\hline Acetate kinase & MS0652 & MHJ0505 & MHP0508 \\
\hline $\begin{array}{l}\text { Riboflavin kinase / FMN } \\
\text { adenylyltransferase }\end{array}$ & MS0563 & МHJ0270 & MHP0278 \\
\hline Thymidylate kinase & MS0052 & МНJ0251 & МHP0259 \\
\hline $\begin{array}{l}\text { Ribose-phosphate } \\
\text { pyrophosphokinase }\end{array}$ & MS0150 & МHJ0654 & MHP0654 \\
\hline Glycerol kinase & - & MHJ0355 & MHP0359 \\
\hline Glucokinase & - & МHJ0515 & МHP0517 \\
\hline $\begin{array}{l}\text { 5-dehydro-2-deoxyglucono } \\
\text { kinase }\end{array}$ & - & МHJ0220 & МHP0226 \\
\hline
\end{tabular}


of $M$. hyopneumoniae (7448) were also identified in the nonpathogenic strain $(\mathrm{J})$. This finding could be explained by the fact that such enzymatic activities may be essential to Mollicutes which have a reduced metabolism.

\section{Kinase classification}

The classification of kinases found in $M$. hyopneumoniae strains $\mathrm{J}$ and 7448 , as well as in $M$. synoviae was performed according to the description of Cheek et al. (2005). Here, the definition of kinase was restricted to enzymes which catalyze the transfer of the terminal phosphate group from ATP to a substrate containing an alcohol, nitrogen, carboxyl or phosphate group as phosphoryl acceptor. The classification scheme lists a total of 25 kinase family homologues which are assembled into 12 groups based on the similarity of the structural fold. Within a fold group, the core of the nucleotide-binding domain of each family has the same architecture, and the topology of the protein core is either identical or related by circular permutation (Cheek et al., 2005). In the two $M$. hyopneumoniae strains and in the $M$. synoviae strain the 47 identified ORFs code for 18 different kinases classified in nine families. These were grouped into five fold groups, as shown in Table 2. Fold Group 2 (Rossmann-like) contains 11 enzymes divided into five families, in which all the seven members of the P-loop kinase family are proteins involved in purine and pyrimidine metabolism. The remaining four members of this group are fall into four families which, together with four members of Group 4 and a member of Group 5 (TIM b /a barrel kinase) are involved in the carbohydrate metabolism. Group 1 (Protein S/T-Y kinase) and Group 8 (Riboflavin kinase) are each represented by one enzyme only, which participate in signaling cascades and riboflavin metabolism, respectively.

\section{Nucleotide metabolism and kinases}

Mollicutes are unable to synthesize purines and pyrimidines by de novo pathways, and guanine, guanosine, uracil, thymine, thymidine, cytidine, adenine and adenosine may serve as precursors for nucleic acids, and nucleotide coenzymes in these organisms (Himmelreich et al., 1996). They only synthesize ribonucleotides by the salvage pathway. In the complete genome of $M$. hyopneumoniae and $M$. synoviae we identified six kinases in the first one and seven kinases in the second one, all of which catalyze key steps in the nucleotide salvage pathway. Deoxyribonucleotides are produced from ribonucleotides by a ribonucleoside diphosphate reductase. Adenine, guanine and uracil can be metabolized to the corresponding nucleoside monophosphate by adenine phosphoribosyltransferase, hypoxanthine-guanine phosphoribosyltransferase and uracil phosphoribosyltransferase, respectively. ADP, GDP, UDP and CDP are generated by adenylate, guanylate, uridylate and cytidylate kinases. Only $M$. synoviae has three ORFs encoding deoxyguanosine kinase, which can convert deoxyguanosine to dGMP. However, a nucleotide diphosphate kinase (ndk), the main enzyme for the production of NTP from NDP, was not found in the $M$. hyopneumoniae and M. synoviae genomes. This finding is in agreement with data from other Mollicutes genome sequences. It was proposed that the absence of an ndk gene ortholog in Mollicutes could be compensated by 6-phos-

Table 2 - Classification of M. synoviae and M. hyopneumoniae kinase activities by family and fold group*.

\begin{tabular}{|c|c|c|c|}
\hline Fold Group & Family & PFAM members $^{+}$ & Kinase activity (EC) \\
\hline $\begin{array}{l}\text { Group 1: protein S/T-Y kinase/ atypical } \\
\text { protein kinase/ lipid kinase/ ATP-grasp }\end{array}$ & Protein S/T-Y kinase & PF00069 & 2.7.1.37 Serine/threonine protein kinase \\
\hline \multirow[t]{10}{*}{ Group 2: Rossmann-like } & P-loop kinases: & PF00406 & 2.7.4.3 Adenylate kinase \\
\hline & & PF00265 & 2.7.1.21 Thymidine kinase \\
\hline & & PF01712 & 2.7.1.113 Deoxyguanosine kinase \\
\hline & & PF02224 & 2.7.4.14 Cytidylate kinase \\
\hline & & PF00625 & 2.7.4.8 Guanylate kinase \\
\hline & & PF00696 & 2.7.4.- Uridylate kinase \\
\hline & & PF02223 & 2.7.4.9 Thymidylate kinase \\
\hline & Phosphoglycerate kinase: & PF00162 & 2.7.2.3 Phosphoglycerate kinase \\
\hline & Phosphofructokinase-like: & PF00365 & 2.7.1.11 6-phosphofructokinase \\
\hline & Ribokinase-like: & PF00294 & 2.7.1.92 5-dehydro-2-deoxygluconokinase \\
\hline \multirow[t]{4}{*}{ Group 4: ribonuclease H-like } & Ribonuclease H-like & PF00480 & 2.7.1.60 N-acetylmannosamine kinase \\
\hline & & PF00871 & 2.7.2.1 Acetate kinase \\
\hline & & PF00370 & 2.7.1.30 Glycerol kinase \\
\hline & & PF02685 & 2.7.1.2 Glucokinase \\
\hline Group 5: TIM $\beta / \alpha$ ? barrel kinase & TIM $\beta / \alpha$ ? barrel kinase & PF00224 & 2.7.1.40 Pyruvate kinase \\
\hline Group 8: riboflavin kinase & Riboflavin kinase & PF01687 & 2.7.1.26 Riboflavin kinase \\
\hline
\end{tabular}

*The classification was based on Cheek et al. (2005). 
phofructokinases, phosphoglycerate kinases, pyruvate kinases, and acetate kinases. In addition, besides reactant ADP/ATP, these organisms could use other ribo- and deoxyribo-purine and pyrimidine NDPs and NTPs (Pollack et al., 2002).

Like in $M$. penetrans, important enzymes such as uridine kinase and pyrimidine nucleoside phosphorylase, which convert cytosine in CMP, are also missing in the two species. The synthesis of CTP from UTP by CTP synthetase is possible only in two M. hyopneumoniae strains. The production of deoxythymidine diphosphate from thymidine may be performed by thymidine and thymidylate kinases. A gene encoding ribose-phosphate pyrophosphokinase is present and this enzyme would produce 5-phosphoribosyl diphosphate, a crucial component in nucleotide biosynthesis. All kinases involved in the nucleotide salvage pathway are fall into fold Group 2. Moreover, only ribosephosphate pyrophosphokinase is not in the P-loop kinases family of this group.

\section{Kinases involved in the metabolism of carbohydrates}

Both M. hyopneumoniae and M. synoviae have the entire set of genes responsible for glycolysis. Like in $M$. pulmonis (Chambaud et al., 2001), M. hyopneumoniae strain 232 (Minion et al., 2004), and M. mobile (Jaffe et al., 2004), glycolysis in M. hyopneumoniae J and 7448 can begin by direct phosphorylation of glucose by glucokinase (Group 4; ribonuclease H-like family) activity. Alternatively, as described for other Mollicutes (Fraser et al., 1995; Himmelreich et al., 1996; Glass et al., 2000), M. synoviae produces glucose 6-posphate only by the action of phosphoenolpyruvate-dependent sugar phosphotransferase system. The two species M. hyopneumoniae and M. synoviae have a 6-phosphofructokinase (Group 2; phosphofructokinase-like family), phosphoglycerate kinase (Group 2; phosphoglycerate kinase family) and pyruvate kinase (Group 5; TIM $\beta / \alpha$ ? barrel kinase family). These three key enzymes also participate in the glycolysis pathway, like in other Mollicutes. In addition, they have an acetate kinase (Group 4; ribonuclease H-like family), an essential enzyme in the production of acetyl-CoA from acetate.

Even though, M. synoviae and M. hyopneumoniae strains have glycerol transporter-related proteins, only the second species presents a glycerol kinase (Group 4; ribonuclease H-like family) enzyme which could directly convert glycerol to glycerol 3-phosphate. This product is then converted into glyceraldehyde 3-phosphate.

In their amino sugar metabolism, mycoplasmas can produce fructose 6-phosphate (F6P) also from N-acetyl-Dglucosamine. In this pathway, $M$. synoviae N-acetylmannosamine kinase (Group 4; ribonuclease H-like family) catalyzes a key reaction in the production of F6P from $\mathrm{N}$-acetyl-neuraminate. Even though both species lack the inositol metabolism pathway, only $M$. hyopneumoniae presents a 5-dehydro-2-deoxygluconokinase (Group 2; Thia- min pyrophosphokinase family), an enzyme which catalyzes a step in this pathway. The presence of specific kinases in the M. synoviae and M. hyopneumoniae (strain J and 7448) genomes shows the possibility for the use of different metabolic routes by each mycoplasma in response to the specific nutritional conditions found by each pathogen in its respective host environment.

\section{Riboflavin metabolism and kinases}

M. hyopneumoniae and $M$. synoviae lack enzymes that synthesize many coenzymes and cofactors. However, they produce Flavine Adenine Dinucleotide (FAD) from riboflavin. This process is performed in two steps where, in the first step, riboflavin kinase phosphorylates riboflavin to form flavin mononucleotide (FMN). Next, FMN is converted to flavin adenine dinucleotide (FAD) by a FMN adenylyltransferase (Karthikeyan, et al., 2003). FAD is an enzyme cofactor used in several metabolic pathways. In $M$. synoviae and $M$. hyopneumoniae, the two steps are performed by a single bifunctional enzyme riboflavin kinase/ FMN adenylyltransferase, as occurs also in bacteria (Manstein et al., 1986; Mack et al., 1998). It is a unique enzyme and the only representative for fold Group 5.

\section{Amino acid sequence relationships}

In order to investigate the phylogenetic relationships of the kinase families of $M$. synoviae 53, M.hyopneumoniae $\mathrm{J}$ and M.hyopneumoniae 7448, the 47 deduced amino acid sequences of the ORFs encoding kinases were aligned using the ClustalX 1.81 program. Robustness of branches was estimated by using 100 bootstrap replicates.

Figure 1 shows the phylogenetic tree for kinases as calculated from the neighbour-joining method. The tree was rooted with Group 1 since it has only one representative. The kinase sequences were well resolved into clades. The P-loop kinase family of Group 2 (Rossmann-like) was clustered into four subclades (Figure 1, letters A, B, C and D). The subclades B and C comprise sequences from $M$. synoviae, M. hyopneumoniae $\mathrm{J}$ and $M$. hyopneumoniae 7448 implicated in phosphorylation of the monophosphate nucleotides. Thymidylate kinase and deoxiguanosine kinase convert TMP to TDP and deoxiguanosine to dGMP, respectively. Although these enzymes have different functions, they have structurally similar nucleotide-binding domains following the classification described by Cheek et al., (2005). The other members of the Rossmann-like Group, which are the phosphoglycerate kinase, ribokinase-like and thiamine pyrophosphokinase families, clustered in individual groups. The sequences from Group 4 formed four clades. Although belonging to the same fold group they are implicated in different metabolic pathways.

\section{Concluding Remarks}

In the complete genomes of $M$. synoviae strain 53, $M$. hyopneumoniae strains J and 7448 we identified kinases in- 


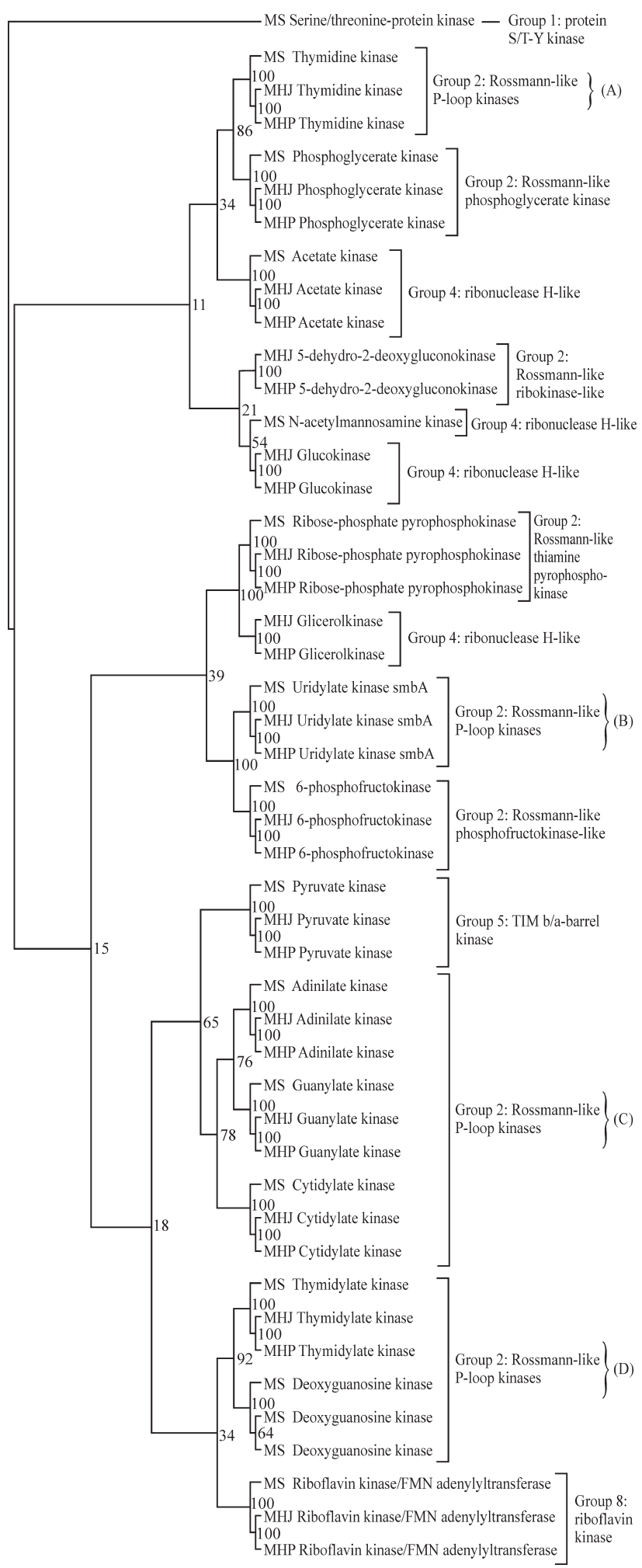

Figure 1 - Phylogenetic tree obtained from kinase amino acid sequence relationships. The kinase fold groups and families are shown in brackets on the right side. The Group 2: Rossmann-like P-loop kinases were clustered into four sub-groups (A, B, C and D). The numbers on the branches are bootstrap values obtained with 100 replications. The kinase encoding ORFs are represented by MSkinase (M. synoviae), MHJkinase ( $M$. hyopneumoniae J) and MHPkinase (M. hyopneumoniae 7448). volved in many essential metabolic pathways such as carbohydrates, purine, pyrimidine and cofactors metabolism. The presence of those enzymes evidenced the metabolic machinery utilized by these organisms which are considered minimalist models.

\section{Acknowledgments}

This work was performed within the Brazilian National Genome Program (Southern Network for Genome Analysis and Brazilian National Genome Project Consortium) with funding provided by $\mathrm{MCT} / \mathrm{CNPq}$ and SCT/FAPERGS (RS).

\section{References}

Allen JL, Noormohammadi AH and Browning GF (2005) The vlhA loci of Mycoplasma synoviae are confined to a restricted region of the genome. Microbiology 151:935-940.

Altschul SF, Madden TL, Schaffer AA, Zhang J, Zhang Z, Miller W and Lipman DJ (1997) Gapped BLAST and PSI-BLAST: A new generation of protein database search programs. Nucleic Acids Res 25:3389-3402.

Assuncao P, De la Fe C, Ramirez AS, Llamazares OG and Poveda JB (2005) Protein and antigenic variability among Mycoplasma hyopneumoniae strains by SDS-PAGE and immunoblot. Vet Res Commun 29:563-574.

Berent LM and Messick JB (2003) Physical map and genome sequencing survey of Mycoplasma haemofelis (Haemobartonella felis). Infect Immun 71:3657-3662.

Chambaud I, Heilig R, Ferris S, Barbe V, Samson D, Galisson F, Moszer I, Dybvig K, Wroblewski H, Viari A, Rocha EP and Blanchard A (2001) The complete genome sequence of the murine respiratory pathogen Mycoplasma pulmonis. $\mathrm{Nu}-$ cleic Acids Res 29:2145-2153.

Chambaud I, Wroblewski H and Blanchard A (1999) Interactions between mycoplasmas lipoproteins and the host immune system. Trends Microbiol 7:493-499.

Cheek S, Ginalski K, Zhang H and Grishin NV (2005) A comprehensive update of the sequence and structure classification of kinases. BMC Struct Biol 5:6.

Ciprian A, Pijoan C, Cruz T, Camacho J, Tortora J, Colmenares G, Lopez RR and de la Garza M (1988) Mycoplasma hyopneumoniae increases the susceptibility of pigs to experimental Pasteurella multocida pneumonia. Can J Vet Res 52:434-438.

Citti C and Rosengarten R (1997) Mycoplasma genetic variation and its implication for pathogenesis. Wiener Klin Wochensch 109:562-568.

Eddy SR (1998) Profile hidden Markov models. Bioinformatics 14:755-763.

Fraser CM, Gocayne JD, White O, Adams MD, Clayton RA, Fleischmann RD, Bult CJ, Kerlavage AR, Sutton G, Kelley JM, Fritchman RD, Weidman JF, Small KV, Sandusky M, Fuhrmann J, Nguyen D, Utterback TR, Saudek DM, Phillips CA, Merrick JM, Tomb JF, Dougherty BA, Bott KF, Hu PC, Lucier TS, Peterson SN, Smith HO, Hutchison CA 3rd and Venter JC (1995) The minimal gene complement of Mycoplasma genitalium. Science 270:397-403. 
Glass J, Lefkowitz EJ, Glass JS, Heiner CR, Chen EY and Cassell GH (2000) The complete sequence of the mucosal pathogen Ureaplasma urealyticum. Nature 407:757-762.

Himmelreich R, Hilbert H, Plagens H, Pirkl E, Li BC and Herrmann R (1996) Complete sequence analysis of the genome of the bacterium Mycoplasma pneumoniae. Nucleic Acids Res 24:4420-4449.

Jaffe JD, Stange-Thomann N, Smith C, DeCaprio D, Fisher S, Butler J, Calvo S, Elkins T, FitzGerald MG, Hafez N, Kodira CD, Major J, Wang S, Wilkinson J, Nicol R, Nusbaum C, Birren B, Berg HC and Church GM (2004) The complete genome and proteome of Mycoplasma mobile. Genome Res 14:1447-1461.

Karthikeyan S, Zhou Q, Osterman AL and Zhang H (2003) Ligand binding-induced conformational changes in riboflavin kinase: Structural basis for the ordered mechanism. Biochemistry 43:12532-12538.

Mack M, van Loon AP and Hohmann HP (1998) Regulation of riboflavin biosynthesis in Bacillus subtilis is affected by the activity of the flavokinase/flavin adenine dinucleotide synthetase encoded by ribC. J Bacteriol 180:950-955.

Maniloff J (1992) Phylogeny of mycoplasmas. In: Maniloff J, Finch LR and Baseman JB (eds) Mycoplasmas: Molecular Biology and Pathogenesis. American Society for Microbiology, Washington, pp 549-559.

Manstein DJ and Pai EF (1986) Purification and characterization of FAD synthetase from Brevibacterium ammoniagenes. J Biol Chem 261:16169-16173.

Minion FC, Lefkowitz EJ, Madsen ML, Cleary BJ, Swartzell SM and Mahairas GG (2004) The genome sequence of Mycoplasma hyopneumoniae strain 232, the agent of swine mycoplasmosis. J Bacteriol 186:7123-7133.

Morowitz HJ (1984) The completeness of molecular biology. Isr J Med Sci 20:750-753.

Muhlradt PF (2002) Immunomodulation by mycoplasmas: Artifacts, facts and active molecules. In: Razin S and Herrmann R (eds) Molecular Biology and Pathogenicity of Mycoplasmas. Kluwer Academic/Plenum Publishers, New York, pp 445-472.

Nocard E and Roux ER (1898) Le microbe de la peripneumonie. Ann Inst Pasteur 12:240-262.

Papazisi L, Gorton TS, Kutish G, Markham PF, Browning GF, Nguyen DK, Swartzell S, Madan A, Mahairas G and Geary SJ (2003) The complete genome sequence of the avian pathogen Mycoplasma gallisepticum strain $\mathrm{R}_{\text {(low) }}$. Microbiology 149:2307-2316

Pollack JD, Myers MA, Dandekar T and Herrmann R (2002) Suspected utility of enzymes with multiple activities in the small genome Mycoplasma species: The replacement of the missing "household" nucleoside diphosphate kinase gene and activity by glycolytic kinases. OMICS 6:247-58

Rogers MJ, Simmons J, Walker RT, Weisburg WG, Woese CR, Tanner RS, Robinson IM, Stahl DA, Olsen G, Leach RH and Maniloff J (1985) Construction of mycoplasma evolutionary tree from 5S rRNA sequence data. Proc Natl Acad Sci USA 82:1160-1164.

Ross RF (1992) Mycoplasmal disease. In: Leman AD, Straw BE, Mengeling WL, D'Allaire S and Taylor DJ (eds) Diseases of Swine. Iowa State University Press, Ames, pp 537-551.
Saitou N and Nei M (1987) The neighbor-joining method: A new method for reconstructing phylogenetic trees. Mol Biol Evol 4:406-425.

Sasaki Y, Ishikawa J, Yamashita A, Oshima K, Kenri T, Furuya K, Yoshino C, Horino A, Shiba T, Sasaki T and Hattori M (2002) The complete genome sequence of Mycoplasma penetrans, an intracellular bacterial pathogen in humans. Nucleic Acids Res 30:5293-5300.

Shen X, Gumulak J, Yu H, French CT, Zou N and Dybvig K (2000) Gene rearrangements in the $v$ sa locus of Mycoplasma pulmonis. J Bacteriol 182:2900-2908.

Thacker EL, Halbur PG, Ross RF, Thanawongnuwech R and Thacker BJ (1999) Mycoplasma hyopneumoniae potentiation of porcine reproductive and respiratory syndrome virus-induced pneumonia. J Clin Microbiol 37:620-627.

Thompson JD, Gibson TJ, Plewniak F, Jeanmougin F and Higgins DG (1997) The ClustalX windows interface: Flexible strategies for multiple sequence alignment aided by quality analysis tools. Nucleic Acids Res 24:4876-4882.

Vasconcelos AT, Ferreira HB, Bizarro CV, Bonatto SL, Carvalho MO, Pinto PM, Almeida DF, Almeida LG, Almeida R, Alves-Filho L, Assuncao EN, Azevedo VA, Bogo MR, Brigido MM, Brocchi M, Burity HA, Camargo AA, Camargo SS, Carepo MS, Carraro DM, de Mattos Cascardo JC, Castro LA, Cavalcanti G, Chemale G, Collevatti RG, Cunha CW, Dallagiovanna B, Dambros BP, Dellagostin OA, Falcao C, Fantinatti-Garboggini F, Felipe MS, Fiorentin L, Franco GR, Freitas NS, Frias D, Grangeiro TB, Grisard EC, Guimaraes CT, Hungria M, Jardim SN, Krieger MA, Laurino JP, Lima LF, Lopes MI, Loreto EL, Madeira HM, Manfio GP, Maranhao AQ, Martinkovics CT, Medeiros SR, Moreira MA, Neiva M, Ramalho-Neto CE, Nicolas MF, Oliveira SC, Paixao RF, Pedrosa FO, Pena SD, Pereira M, Pereira-Ferrari L, Piffer I, Pinto LS, Potrich DP, Salim AC, Santos FR, Schmitt R, Schneider MP, Schrank A, Schrank IS, Schuck AF, Seuanez HN, Silva DW, Silva R, Silva SC, Soares CM, Souza KR, Souza RC, Staats CC, Steffens MB, Teixeira SM, Urmenyi TP, Vainstein MH, Zuccherato LW, Simpson AJ and Zaha A (2005) Swine and poultry pathogens: The complete genome sequences of two strains of Mycoplasma hyopneumoniae and a strain of Mycoplasma synoviae. J Bacteriol 187:5568-5577.

Westberg J, Persson A, Holmberg A, Goesmann A, Lundeberg J, Johansson KE, Pettersson B and Uhlén M (2004) The genome sequence of Mycoplasma mycoides subsp. mycoides SC type strain $\mathrm{PG}^{\mathrm{T}}$, the causative agent of contagious bovine pleuropneumonia. Genome Res 14:221-227.

Woese CR, Maniloff J and Zablin LB (1980) Phylogenetic analysis of the mycoplasmas. Proc Natl Acad Sci USA 77:494498.

\section{Internet Resources}

M. synoviae complete genome database, http://www.brgene.lncc. br/finalMS/.

M. hyopneumoniae strain J and M. hyopneumoniae strains 7448 complete genomes databases, http://www.genesul.lncc.br.

BLAST tools, http://www.ncbi.nlm.nih.gov/blast.

Database of protein families (Pfam), http://www.sanger.ac.uk/ Software/Pfam/.

InterProScan software, http://www.ebi.ac.uk/InterProScan/. Associate Editor: Arnaldo Zaha 